\section{Air angiogram}

Air embolism during pacemaker implantation is a rare but potentially fatal complication. ${ }^{1}{ }^{2}$ The creation of negative intrathoracic pressure sucking up air seems to be the most common mechanism of this event. ${ }^{3}$ Air embolism during the use of sheaths with haemostatic valves is a very rare occurrence.

An 80-year-old man was undergoing implantation of cardiac resynchronisation therapy device (BIOTRONIK Stratos LV-T). Under fluoroscopy, a 7 French peel-away introducer with a haemostasis valve for left ventricular lead delivery (BIOTRONIK Scoutpro) was introduced after left subclavian vein puncture. During coronary sinus engagement, the patient had a bout of cough; subsequently, a large volume of air was sucked in through the valved sheath. The air opacified the entire right ventricular outflow tract and the pulmonary artery (which was captured real time in cine images) (figure 1 and online supplementary video 1 ). Surprisingly the patient did not show any signs of a haemodynamic compromise and the air was quickly absorbed. The procedure was completed successfully (online supplementary video 2) and the patient was discharged eventually.

The creation of a high negative intrathoracic pressure caused the air to be sucked in, leading to a potentially life-threatening complication which was recorded on cinefluoroscopy. Such a mechanism is very rare in case of sheaths with homoeostatic valves. In the event of a haemodynamic compromise, conservative treatment is the mainstay of management. In order to prevent such complications it is reasonable to keep good preoperative hydration, to avoid sedation, to ask the patient to hold her breath during insertion of sheaths and to cover the mouth of the sheath with a thumb when there are chances of large negative intrathoracic pressure sucking air in (coughing, deep respiration, snoring, etc).

\section{Amit Malviya, Dhanjit Nath, Animesh Mishra}

Department of Cardiology, North Eastern Indira Gandhi Regional Institute of Health and Medical Sciences (NEIGRIHMS), Shillong, Meghalaya, India

Correspondence to Dr Amit Malviya, Department of Cardiology, North Eastern Indira Gandhi Regional Institute of Health and Medical Sciences (NEIGRIHMS),

Shillong, Meghalaya 793018, India; dramit_malviya@rediffmail.com

Contributors All authors were actively involved in the care and management of the patient as well as in drafting, revision and final approval of the manuscript.

Competing interests None.

Patient consent Obtained.

Provenance and peer review Not commissioned; internally peer reviewed.

- Additional material is available. To view please visit the journal (http://dx.doi.org/ 10.1136/heartasia-2014-010550).

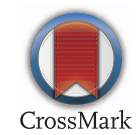

To cite Malviya A, Nath D, Mishra A. Heart Asia 2014;6:108. doi:10.1136/ heartasia-2014-010550

Heart Asia 2014;6:108. doi:10.1136/heartasia-2014-010550

\section{REFERENCES}

1 Cooper JP, Swanton RH. Complications of transvenous temporary pacemaker insertion. Br J Hosp Med 1995;53:155-61.

2 Turgeman Y, Antonelli D, Atar S, et al. Massive transient pulmonary air embolism during pacemaker implantation under mild sedation: an un-recognized hazard of snoring. Pacing Clin Electrophysiol 2004;27:684-5.

3 Xiao PX, Hu ZY, Zhang $\mathrm{H}$, et al. Massive pulmonary air embolism during the implantation of pacemaker, case reports and literature analysis. Eur Rev Med Pharmacol Sci 2013;17:3157-63.
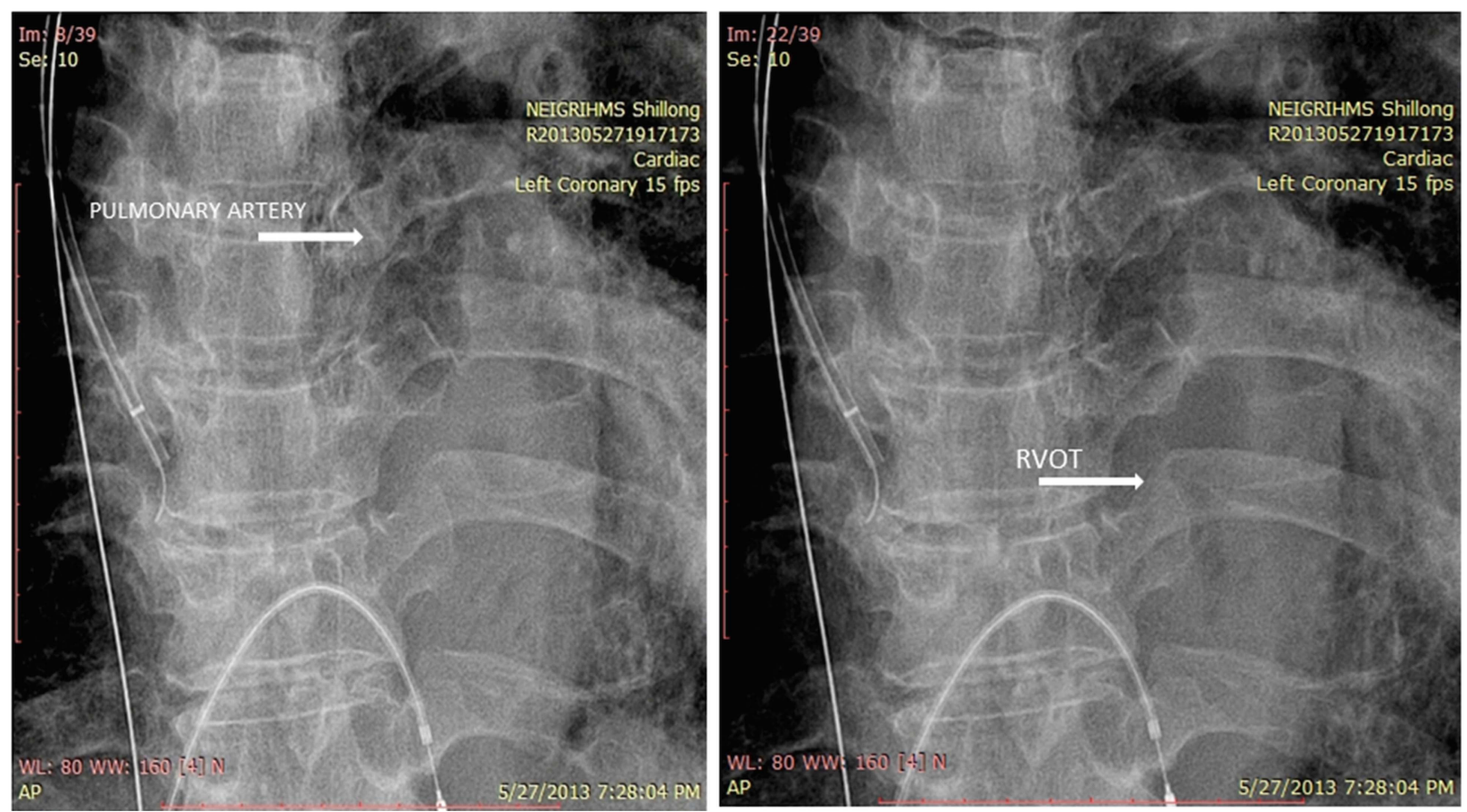

Figure 1 Cine images showing passage of air from the right ventricular outflow to the pulmonary artery and thus opacifying it completely. The temporary pacing lead and sheath can be seen. 